(REVIEW ARTICLE)

\title{
Community pharmacists' role as antibiotic stewards in the fight against coronavirus disease 2019
}

\author{
Michelo Banda *, Vianney Neene and Steward Mudenda \\ University of Zambia, School of Health Sciences, Department of Pharmacy, P.O Box 50110, Lusaka, Zambia.
}

Publication history: Received on 19 August 2020; revised on 19 September 2020; accepted on 21 September 2020

Article DOI: https://doi.org/10.30574/wjarr.2020.8.1.0312

\begin{abstract}
Antibiotic misuse and overuse are key drivers of antimicrobial resistance. One common practice that leads to antibiotic misuse is self-medication. Antibiotics have been misused for viral respiratory tract conditions such as cold and flu. The misuse of antibiotics could extend to mild infections of coronavirus disease (COVID-19), further driving up antimicrobial resistance. COVID-19 emerged a global health problem that originated from Wuhan City in Hubei province of China. Community pharmacists, due to their constant and direct contact with patients, can implement several measures that can drive down the misuse of antibiotics during the COVID-19 pandemic. This article highlights the roles of community pharmacists as antimicrobial stewards that should not be neglected during and after the pandemic.
\end{abstract}

Keywords: Antimicrobial resistance; Community pharmacists; Coronavirus disease 2019; COVID-19; Pandemic; Selfmedication

\section{Introduction}

Antimicrobial resistance (AMR) is a global health issue that is highly correlated with antibiotic misuse and overuse [14]. One of the main ways in which antibiotics are misused with the potential to cause antibiotic resistance is through self-medication [5].

The factors contributing to AMR are many, though patients have a hand in driving it up as they demand antibiotics to treat common cold and flu [5,6]. This could be due to misplaced beliefs about the use of antibiotics for treating viral infections [7]. One survey carried out in 2015 by the World Health Organisation (WHO) highlighted this fallacy, as it found that $64 \%$ of 10,000 respondents thought that antibiotics were effective against common cold and flu [8]. The WHO survey also revealed several beliefs and practices among the general public that have the potential to fuel the problem of AMR. This included the use of leftover antibiotics, the purchase of antibiotics that were effective for a previous illness with the same symptoms or asking the doctor for a prescription, and also, not completing an antibiotic treatment course when they felt better [8].

Coronavirus disease 2019 (COVID-19) is a respiratory tract infection caused by severe acute respiratory syndrome coronavirus 2 (SARS-CoV-2) that originated from Wuhan City in the Hubei province of China [9]. Some of the symptoms of COVID-19 include fever, dry cough, sore throat, chest pain, shortness of breath, nausea, vomiting, diarrhoea, and respiratory failure [10].

\footnotetext{
${ }^{*}$ Corresponding author: Michelo Banda, Phone \#: +260977422253, Email: michelobanda@gmail.com

University of Zambia, School of Health Sciences, Department of Pharmacy, P.O Box 50110, Lusaka, Zambia.
} 


\subsection{Increased antibiotic consumption during the COVID-19 pandemic}

The advent of the coronavirus disease 2019 (COVID-19) pandemic has further enhanced the problem of antibiotic resistance, as there has been an increase in antibiotic use despite COVID-19 being a viral infection [11, 12]. A study in Asia brought this issue to light as findings showed that over $70 \%$ of patients being treated for COVID-19 received broadspectrum antibiotics despite only $8 \%$ having a bacterial or fungal co-infection [13]. It is evident that antibiotics are being used for COVID-19 and this calls for prudent and appropriate use of antibiotics [14].

The media hype regarding the possibility of the use of antibiotics such as azithromycin for COVID-19 despite lack of evidence has made the fight against antibiotic resistance even more challenging [11]. There have been multiple reports of shortages of drugs that the media have purported have activity against COVID-19 $[15,16]$. Due to the media reports, many prescribers have been forced to increase the prescribing of antibiotics [16]. The media reports, most patients with respiratory tract diseases are seeking the use of antibiotics [11]. This increase in the prescribing of antibiotics and increased patient demands for antibiotics will eventually accelerate antibiotic resistance.

\subsection{Community pharmacists as antibiotic stewards}

The mild symptoms of COVID-19 are similar to those of other upper respiratory tract viral infections, such as mild fever, dry cough, sore throat, nasal congestion, muscle pain, and malaise [17]. Before the COVID-19 pandemic, some respiratory infections that did not require treatment using antibiotics were still treated with antibiotics $[18,19]$. The WHO has discouraged the use of antibiotics for mild cases of COVID-19 [11]. However, the media hype regarding the use of azithromycin against COVID-19, previous antibiotic prescribing practices, and the similarities between upper respiratory tract viral infections and COVID-19 may compel some of the general public to seek antibiotics for treatment.

Community pharmacists are in an ideal position to help combat AMR by reducing antibiotic misuse and overuse, as they are in constant direct contact with patients [20]. A WHO report revealed that most of the general public obtain their drugs from a pharmacy or medical store [8]. Hence, this shows that community pharmacists are vital healthcare professionals even during pandemics.

Community pharmacists have many roles in the fight against COVID-19 [21]. Community pharmacists should, however, not neglect their roles in the fight against AMR. Community pharmacists can help to promote the rational use of antibiotics by implementing the recommendations and measures as guided by the International Pharmaceutical Federation (FIP) [22]. Some recommended roles of community pharmacists in the fight against AMR have been cited in Table 1.

Table 1 shows the recommendations on the roles of community pharmacists in the fight against antimicrobial resistance.

Community pharmacists play key roles in reducing the threat of AMR as they are gatekeepers of antibiotics in the community [25-30]. In some countries, over-the-counter purchase of antibiotics is legal and community pharmacists provide treatment responsibly and within an appropriate legal framework [20]. Therefore, it is important to recognize the roles of community pharmacists in the fight against COVID-19 and AMR. 
Table 1 Recommended roles of Community Pharmacists in the fight against Antimicrobial Resistance

\section{Recommendation}

Recommend other therapies such as lozenges and not antimicrobials that patients can take for the symptomatic treatment of viral respiratory illness for sore throat and coughs [23].

Educate patients on the appropriate use of antibiotics, their adverse reactions and interactions, and antimicrobial resistance [24].

Patients should be reminded of the lack of the role of antibiotics in the management of viral infections [23].

Educate patients about the right way of using antibiotics by discouraging self-medication, use, or storage for future use, of leftover antimicrobial medicines [6, 8].

Advising a consumer to never demand antibiotics if a health worker says they are not necessary [8].

Ensure that all necessary information is written and proper counselling advice is given when dispensing antimicrobial medicines [22].

Encourage patients to only take antibiotics when prescribed by a certified health professional, and to take them as directed by the prescriber, including completing the treatment course even when they feel better before completion $[8,22]$.

Countercheck that antimicrobials are prescribed to the right person for the correct duration at the correct dose and frequency, opting for the narrowest spectrum agents where possible [22].

Educate patients on measures they can take to prevent infections such as vaccination, hand washing, safer sex, and covering nose and mouth when sneezing $[6,8]$.

Advise antimicrobial consumers on how they should dispose of unused medicine [22].

Take active roles in "return and disposal" programmes designated for the appropriate disposal of expired or unused antimicrobial medicines [22].

Plan and actively participate in health education campaigns that surround issues of maintaining antimicrobial effectiveness among prescribers, patients, veterinary and agriculture sectors [22].

Source antimicrobial medicines from reliable sources that are of good quality, safe and efficacious, and avoid procuring counterfeit medicines [22, 24].

Ensure that the supply of antimicrobial medicines for human use or animal use adhere to country legislation and regulations [22].

Ensure uninterrupted and fast supply of antibiotics to avoid under-treatment, and adhere to best dispensing practices including the non-prescription sale of antibiotics, non-sale of partial antibiotic doses, and repeat prescriptions for antimicrobials [20].

Work hand in hand with governments to ensure adequate legislative control over the provision of antimicrobial medicines [22].

Conduct and translate research on all areas of antimicrobial resistance and antimicrobial stewardship in the One Health approach [14,22].

\section{Conclusion}

The roles of community pharmacists in the fight against AMR during the COVID-19 pandemic in this article are not exhaustive and should not be limited to being practised during the pandemic era. This article shows some of the key contributions pharmacists can make in reducing antibiotic misuse and overuse during the COVID-19 pandemic era. Reducing the misuse and overuse of antibiotics will in turn reduce the medical costs, economic burdens, morbidity and mortality associated with antibiotic resistance. 


\section{Compliance with ethical standards}

\section{Acknowledgments}

We are grateful to the University of Zambia Library for providing access to many articles that we could only access through the institutional Library.

\section{Disclosure of conflict of interest}

The authors declare no conflict of interest.

\section{Author's contributions}

MB and SM conceptualized the initial manuscript. All authors contributed to the development of the initial manuscript. All authors critically reviewed the important intellectual content of the manuscript. All authors read and approved the final version of the manuscript.

\section{References}

[1] Austin DJ, Kristinsson KG, Anderson RM. The relationship between the volume of antimicrobial consumption in human communities and the frequency of resistance. Proceedings of the National Academy of Sciences of the United States of America. 1999; 96(3): 1152-6.

[2] Goossens H, Ferech M, Vander Stichele R, Elseviers M. Outpatient antibiotic use in Europe and association with resistance: a cross-national database study. Lancet (London, England). 2005; 365(9459): 579-87.

[3] Hicks LA, Chien YW, Taylor TH, Jr., Haber M, Klugman KP. Outpatient antibiotic prescribing and nonsusceptible Streptococcus pneumoniae in the United States, 1996-2003. Clinical infectious diseases: an official publication of the Infectious Diseases Society of America. 2011; 53(7): 631-9.

[4] World Health Organisation. Antibiotic resistance. 2018 [updated 5th Feb, 2018; cited 2020 18th May].

[5] Franco BE, Altagracia Martínez M, Sánchez Rodríguez MA, Wertheimer AI. The determinants of the antibiotic resistance process. Infect Drug Resist. 2009; 2: 1-11.

[6] Gaarslev C, Yee M, Chan G, Fletcher-Lartey S, Khan R. A mixed-methods study to understand patient expectations for antibiotics for an upper respiratory tract infection. Antimicrob Resist Infect Control. 2016; 5: 39.

[7] Zulu A, Matafwali SK, Banda M, Mudenda S. Assessment of knowledge, attitude, and practices on antibiotic resistance among undergraduate medical students in the school of medicine at the University of Zambia. Int J Basic Clin Pharmacol. 2020; 9: 263-270.

[8] World Health Organisation. (2015). Antibiotic Resistance: Multi-Country Public Awareness Survey. WHO Press, 1-51. www.who.int.

[9] Kasanga M, Mudenda S, Gondwe T, Chileshe M, Solochi B, Wu J. Impact of COVID-19 on blood donation and transfusion services at Lusaka provincial blood transfusion centre, Zambia. Pan African Medical Journal. 2020; 35(2): 74.

[10] Chinese Center for Disease Control and Prevention. Epidemic update and risk assessment of 2019 Novel Coronavirus 2020 [updated 29 January 2020; cited 202029 February].

[11] Hsu J. How COVID-19 is accelerating the threat of antimicrobial resistance. BMJ. 2020; $369:$ m1983.

[12] Mudenda S. Letter to Editor: Coronavirus Disease (COVID-19): A Global Health Problem. Int J Pharm Pharmacol. 2020; 4(1): 141.

[13] Rawson TM, Moore LSP, Zhu N, Ranganathan N, Skolimowska K, Gilchrist M, et al. Bacterial and fungal co-infection in individuals with coronavirus: A rapid review to support COVID-19 antimicrobial prescribing. Clinical infectious diseases: an official publication of the Infectious Diseases Society of America. 2020; ciaa530.

[14] Huttner BD, Catho G, Pano-Pardo JR, Pulcini C, Schouten J. COVID-19: don't neglect antimicrobial stewardship principles! Clin Microbiol Infect. 2020; S1198-743X(20): 30232-9.

[15] Centres for Disease Control and Prevention. (2020). Azithromycin Shortage. https://www.cdc.gov/std/treatment/drugnotices/azithromycin-2020.htm 
[16] Mehta B, Salmon J, Ibrahim S, editors. Potential Shortages of Hydroxychloroquine for Patients with Lupus during the Coronavirus Disease 2019 Pandemic. JAMA Health Forum. 2020.

[17] Cascella M, Rajnik M, Cuomo A, Dulebohn SC, Di Napoli R. Features, evaluation and treatment coronavirus (COVID-19). StatPearls [internet]: StatPearls Publishing. 2020.

[18] Kalonga J, Hangoma J, Banda M, Munkombwe D, Mudenda S. Antibiotic Prescribing Patterns in Paediatric Patients at Levy Mwanawasa University Teaching Hospital in Lusaka, Zambia. Int J Pharm Pharmacol. 2020; 4(1): 138.

[19] Appropriate Antibiotic Use for Acute Respiratory Tract Infection in Adults: Advice for High-Value Care from the American College of Physicians and the Centers for Disease Control and Prevention. Annals of Internal Medicine. 2016; 164(6): 425-34.

[20] World Health Organisation. The role of pharmacists in encouraging prudent use of antibiotics and averting antimicrobial resistance: a review of policy and experience in Europe. 2014.

[21] Phiri MN, Banda M, Mudenda S, Ngazimbi M, Hangoma J, Mufwambi W, et al. Coronavirus Disease 2019 (COVID19): the role of pharmacists in the Fight against COVID-19 Pandemic. Int J Pharm Pharmacol. 2020; 4(1): 143.

[22] International Pharmaceutical Federation. FIP Statement of Policy- Control of Antimicrobial Resistance (AMR). The Hague: FIP. 2017.

[23] Collins JC, Moles RJ. Management of Respiratory Disorders and the Pharmacist's Role: Cough, Colds, and Sore Throats and Allergies (Including Eyes). Encyclopedia of Pharmacy Practice and Clinical Pharmacy. 2019; 282291.

[24] International Pharmaceutical Federation. Good Pharmacy Practice Joint FIP/WHO Guideline on GPP: Standards for quality of pharmacy services. 2011.

[25] Hangoma JM, Mudenda S, Mwenechanya MM, Kalungia AC. Community pharmacists' knowledge and preparedness to participate in the fight against Coronavirus disease 2019 (COVID-19) in Zambia. MedRxiv. 2020.

[26] Mudenda S, Bangara FF, Sitali J, Banda M. Knowledge, attitude, and practices on antibiotic resistance among Pharmacists at the University Teaching hospitals in Lusaka, Zambia. Journal of Harmonized Research in Pharmacy. 2019; 8: 12-24.

[27] Dickerson LM, Mainous III AG, Carek PJ. The Pharmacist's Role in Promoting Optimal Antimicrobial Use. Pharmacotherapy: The Journal of Human Pharmacology and Drug Therapy. 2000; 20(6): 711-23.

[28] Saleem Z, Hassali MA, Hashmi FK. Pakistan's national action plan for antimicrobial resistance: translating ideas into reality. Lancet Infect Dis. 2018; 18(10): 1066-7.

[29] Mudenda S, Hankombo M, Saleem Z, Sadiq MJ, Banda M, Munkombwe D, Mwila C, Kasanga M, Zulu AC, Hangoma JM, Mufwambi W, et al. Knowledge, Attitude, and Practices of Community Pharmacists on Antibiotic Resistance and Antimicrobial Stewardship in Lusaka, Zambia. MedRxiv. 2020.

[30] Lee $\mathrm{CR}$, Cho IH, Jeong BC, Lee SH. Strategies to minimize antibiotic resistance. International journal of environmental research and public health. 2013; 10(9): 4274-305. 